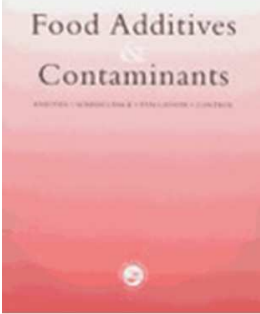

\title{
Immunological detection of osteocalcin in meat and bone meal: a novel heat stable marker for the investigation of illegal feed adulteration
}

\begin{tabular}{|c|c|}
\hline Journal: & Food Additives and Contaminants \\
\hline Manuscript ID: & TFAC-2011-420.R1 \\
\hline Manuscript Type: & Original Research Paper \\
\hline Date Submitted by the Author: & 22-Nov-2011 \\
\hline Complete List of Authors: & $\begin{array}{l}\text { Kreuz, Grit; Federal Institute for Risk Assessment, Food Safety } \\
\text { Zagon, Jutta; Federal Institute for Risk Assessment (BfR), Food Safety } \\
\text { Broll, Hermann; Federal Institute for Risk Assessment, Food Safety } \\
\text { Bernhardt, Christian; Federal Institute for Risk Assessment, Food Safety } \\
\text { Linke, Bettina; Federal Institute for Risk Assessment, Food Safety } \\
\text { Lampen, Alfonso; Federal Institute for Risk Assessment, Food Safety }\end{array}$ \\
\hline Methods/Techniques: & Immunoassays, Traceability, Authenticity \\
\hline Additives/Contaminants: & Animal products, Feeding \\
\hline Food Types: & Animal products - meat, Animal feedingstuffs \\
\hline Abstract: & $\begin{array}{l}\text { A sandwich ELISA was developed for the detection of bovine meat and } \\
\text { bone meal (BMBM) in feed, based on polyclonal rabbit antibodies raised } \\
\text { against the synthetic N-terminal amino acid sequence 1-9 (YLDHWLGAP) } \\
\text { of bovine osteocalcin. To set up a sandwich ELISA pair, a commercial } \\
\text { mouse monoclonal capture antibody binding to a highly conserved epitope } \\
\text { in the mid-fragment of the peptide was employed. It is shown that the } \\
\text { bone marker osteocalcin is immunologically well detectable in BMBM } \\
\text { extracts obtained by a simple EDTA based procedure even in a sample } \\
\text { heated up to } 145 \text { oC. Furthermore a genus-specific restriction of the major } \\
\text { specificity to cattle and horse was possible. The observed bi-specificity is } \\
\text { consistent with theoretical predictions. The assay sensitivity with bovine } \\
\text { osteocalcin of } 1 \text { ng was sufficient to enable the detection of } 0.1 \% \text { BMBM in } \\
\text { compound plant feed or fish meal, for which no cross reaction was } \\
\text { observed. In general the quantification of osteocalcin in extracts is possible } \\
\text { using a standard curve procedure with pure bovine osteocalcin. }\end{array}$ \\
\hline
\end{tabular}




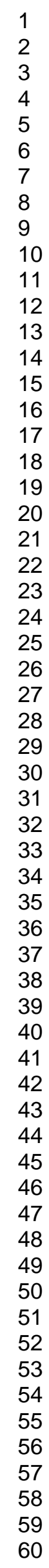

SCHOLARONE"

Manuscripts

7

21

23

24

26

27

29

30

33

34

35

36

39

40

41

43

44

45

46

47

48

50

51

52

53

54

56

57

58

60

http://mc.manuscriptcentral.com/tfac Email: fac@tandf.co.uk 


\section{Immunological detection of osteocalcin in meat and bone meal: a}

2 novel heat stable marker for the investigation of illegal feed

3

4

5

6

7 Federal Institute for Risk Assessment, D-14195 Berlin, Germany

8

9 10

11

12

\author{
G. Kreuz, J. ZaGoN*, H. Broll, C. Bernhardt, B. LinKe, A. LAmpen
}

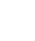

* Corresponding author. E-mail: jutta.zagon@bfr.bund.de

\section{Abstract} is immunologically well detectable in BMBM extracts obtained by a simple EDTA based the major specificity to cattle and horse was possible. The observed bi-specificity is is possible using a standard curve procedure with pure bovine osteocalcin.

A sandwich ELISA was developed for the detection of bovine meat and bone meal (BMBM) in feed, based on polyclonal rabbit antibodies raised against the synthetic $\mathrm{N}$-terminal amino acid sequence 1-9 (YLDHWLGAP) of bovine osteocalcin. To set up a sandwich ELISA pair, a commercial mouse monoclonal capture antibody binding to a highly conserved epitope in the mid-fragment of the peptide was employed. It is shown that the bone marker osteocalcin procedure even in a sample heated up to $145^{\circ} \mathrm{C}$. Furthermore a genus-specific restriction of consistent with theoretical predictions. The assay sensitivity with bovine osteocalcin of $1 \mathrm{ng}$ was sufficient to enable the detection of $0.1 \%$ BMBM in compound plant feed or fish meal, for which no cross reaction was observed. In general the quantification of osteocalcin in extracts 
1

2

3

4

5

6

7

8

9

10

11

12

13

14

15

16

17

18

19

20

21

22

23

24

25

26

27

28

29

30

31

32

33

34

35

36

37

38

39

40

41

42

43

44

45

46

47

48

49

50

51

52

53

54

55

56

57

58

59

60

28 KEYwORDS: Osteocalcin, Meat-and-Bone-Meal (MBM), Bovine spongiform encephalopathy

29 (BSE), Animal feed, Processed animal proteins (PAPs), ELISA, Species identification 
30

31

32

33

34

35

36

37

38

39

40

41

42

43

44

45

46

47

48

49

50

51

52

53

54

55

56

\section{Introduction}

Feeding meat and bone meal (MBM) to farmed animals is prohibited in Europe by Regulation (EC) No 999/2001. In addition, an overarching species-to-species feed ban has been laid down by Regulation (EC) No 1069/2009. The only exemption from the strict MBM ban is fish meal, which has been allowed for pig and fowl feeding and recently also for calves in milk replacing feed mixtures (Regulation (EC) No 999/2001). According to the recitals of the above mentioned Regulation it might be assumed that the feed ban for ruminants will not be lifted in the near future whereas the prohibition of processed animal proteins (PAP) feeding to other animals than ruminants might be relaxed as far as analytical tools for species identification are available.

The official method for the detection of MBM in feeding stuff is based on classical light microscopy (Regulation (EC) No 152/2009). A second test may also be carried out using variant or alternative methods, in order to improve the detection of certain types of animal constituents or to further specify the origin of the animal constituents. The microscopic-based method reliably detects heat- and pressure-stable particles of animal origin like bone fragments, teeth, hair, gills or scales which are resisting the legally required MBM treatment of $133^{\circ} \mathrm{C}$ for $20 \mathrm{~min}$ at $300 \mathrm{kPa}$ (Liu et al. 2011). However, by applying the microscope approach it is not possible to distinguish between species or genus in samples containing PAPs. Thus, up to now the implemented species-to-species ban cannot be controlled. Furthermore, the microscopic investigation depends solely on individual skills and allows an estimation but not quantification of the MBM content in a feed sample. Therefore - and against the background of recently discussed thresholds and a further lifting of the feed ban in the European Union (COMMISSION STAFF WORKING DOCUMENT 2010) - there is an urgent need for alternative methods which might overcome present drawbacks to enable legally consistent feed survey and law enforcement. 
57 The immunological detection of PAPs is for long used as an alternative to microscopy.

58 Immunoassays can be performed in any laboratory independently from sophisticated

59

60

61

62

63

64

65

66

67

68

69

70

71

72

73

74

75

76

77

78

79

80

81

82

83 equipment or particularly trained staff. Antibody based assays are convertible into rapid formats like lateral flow assays (dip stick tests) representing most convenient field methods for rapid screening purposes. Ruminant or pork specific antibodies binding to PAPs, so far have been raised either directly against bovine meat and bone meal (MBM) (Muldoon et al. 2004; Kim et al. 2004), mixtures of muscle proteins (Kim et al. 2005; Chen et al. 1998; Ansfield 1994), purified troponin I (Chen et al. 2002) or $h$-caldesmon (Kim et al. 2004), isolated from skeletal or smooth muscle of the bovine intestine, respectively. Four commercial PAP detecting test kits (two dip stick tests and two ELISA) based on antibodies binding to the described targets have been repeatedly evaluated in studies conducted by official institutions in the USA or Europe. All of them revealed different shortcomings in terms of specificity, selectivity or sensitivity (Fumière et al. 2009). Moreover, from the viewpoint of validation, it is not satisfying that neither the kit manuals nor accompanying scientific publications disclose the precise nature of the targeted epitopes, neither amino acid sequences nor conformational molecular reaction sites, involved in the antigen-antibody binding. As a consequence, potential cross reactivity cannot be deduced in silico and the likelihood to reproduce immunization results obtained with changing or undefined antigen mixtures is low.

\section{The polymerase chain reaction (PCR) is another alternative approach to identify animal} species-specific components in feedstuffs. PCR is highly-specific and is amplifiying target DNA sequences in an exponential way. However PCR is not tissue-specific due to the fact that the DNA of an individual organism does not differ between different tissues. Therefore it is not possible to distinguish if the detected DNA is derived from the use of MBM or from allowed animal products such as milk or egg protein. 
84 In the present study we employed defined target sequences of bovine osteocalcin, consisting

85 of the amino acid sequence 1-9 and the epitope 17 of the peptide, to establish an ELISA for

86

87

88

89

90

91

92

93

94

95

96

97

98

99

100

101

102

103

104

105

106

107

108

109

110 the purpose of MBM detection in feed. Osteocalcin is a small extracellular bone matrix protein produced by osteoblasts and a common constituent in calcified bone tissue all over the vertebrate group including bone fish (Hauschka et al. 1989; Nishimoto et al. 2003; Laizé et al. 2005). The mature peptide of approx. 5800-5900 Da size is composed of $45-49$ amino acids. Up to $90 \%$ of osteocalcin is secreted inside the bone tissue where it is, apart from collagen, the most abundant bone protein accounting up to $2 \mathrm{mg} / \mathrm{g}$ bone matrix or $1-5$ $\%(\mathrm{w} / \mathrm{w})$ of the total bone protein, respectively $10-20 \%(\mathrm{w} / \mathrm{w})$ of the non-collagenous bone proteins (Hauschka et al. 1989). A minor share of osteocalcin (10-40\%) is circulating in the blood where it is - once detached from the bone mineral - quickly degraded in kidney and liver (Lee et al. 2000). The function of osteocalcin is not completely understood but the molecule seems to play a role in the molecular organisation of the hydroxyapatite skeleton as well as in bone turnover (Dowd et al. 2003; Ducy et al. 1996). Three glutamic acid residues are located at amino acid position 17, 21 and 24 , constituting a highly conserved motif of the peptide. These glutamic acids are transformed into $\gamma$-carboxyglutamic acids in a posttranslational carboxylation step and function as precipitation sites for $\mathrm{Ca}^{2+}$ ions. In the presence of calcium the molecule forms a compact structure comprising of two a-helical regions and a hydrophobic core near the C-terminus (Dowd et al. 2003). Both, N- and Cterminal sequences of osteocalcin reveal species specific differences (Figure 1). Osteocalcin is known to be heat stable. Human or bovine bone osteocalcin which was extracted at $120^{\circ} \mathrm{C}$ overnight, lyophilized and decarboxylated at $110^{\circ} \mathrm{C}$ for five hours, still retained its substrate specificity towards enzymatic vitamin K-dependent carboxylase (Vermeer et al. 1984). Osteocalcin could be identified in 75.000-year-old Neanderthal bone by MALDI-TOF/TOF-MS (Nielsen-Marsh et al. 2005) and in fossil bones and teeth by immunoassay-based investigation (Ulrich et al. 1987; Collins et al. 2000; Muyzer et al. 1992). We recently demonstrated that osteocalcin can be identified and differentiated in MBM of 
111 bovine and pig origin using high-resolution (MALDI/TOF-MS and HR-ESI Q/TOF) mass

112 spectrometry (Balizs et al. 2011).

113

114 The aim of the present study was to investigate i) if osteocalcin is still immunologically

115 detectable in MBM treated according to the legal requirements, ii) how far a discrimination of

116 farmed animals, especially cattle in feed, is possible and iii) to evaluate if a selectivity in an

117 ELISA down to $0.1 \%$ MBM either in compound feed or fish meal would be achievable.

118

119 Materials and Methods

120 Materials

121 Pure bovine osteocalcin (OC) was purchased from Merck Calbiochem (Merck, Darmstadt,

122 Germany). Bone from farmed animals and pasteurized egg- and milk powder were

123 purchased from local retailer in Berlin. $100 \%$ pure bovine meat and bone meal (BMBM),

124 treated $145^{\circ} \mathrm{C}$, with a bone content of approx. $80 \%$, as well as $100 \%$ sheep meat and bone

125 meal (OMBM) were kindly submitted by the European Reference Laboratory for Animal

126 Proteins EU-RL AP, Gembloux, Belgium. From the same source a spiked $0.1 \%$ BMBM

127 sample in plant feed (Plant Feed-0.1\% BMBM), serving as reference and training material

128 for microscopists, was obtained. This material was purity checked by classical microscopy

129 and PCR. Based on the results the EU-RL AP specified the material as a mix of four pure

130 bovine meat and bone meals from different heat treatments with a bone content of $\sim 54 \%$.

131 On request, the EU-RL AP also kindly made available a sample of the non-contaminated

132 plant feed background (Plant Feed-0 \% BMBM), used for spiking consisting of a classical

133 feed mix containing wheat, tapioca, soybean, rapeseed, palm kernel and barley meals, beet

134 pulp, molasses, bakery by-products, vegetable fat, limestone, salts and vitamins. A

135 commercial dog feed BMBM (100\% cattle according to the label) was purchased from

136 PerNaturam V.O.F. (Aalten, The Netherlands). Fish meal (FM) and poultry meal (PM)

137 produced under unknown processing parameters were obtained from diverse rendering

138 plants in Germany (SARIA Bio-Industries GmbH \& Co., Selm, Germany). An anonymous 
139 sample of BMBM treated in accordance with legal requirements $\left(133^{\circ} \mathrm{C}\right)$ was obtained from

140 the Department of Feed and Feed Additives of the Federal Institute for Risk Assessment,

141 Berlin. Pure pig meal from an anonymous source was kindly supplied by LUFA Nord-West

142 (Oldenburg, Germany). Samples containing 0.1, 1 and $10 \%(v / v)$ BMBM (dog feed) extract

143 were prepared by mixing respective volumes of MBM extracts containing a comparable total

144 protein concentration.

145

146 Sample preparation and protein extraction

147 For the production of reference proteins, native bones from different species were cleaned

148 from any fat, meat residues and bone marrow and roughly trenched. Bone fragments were

149 degreased by Soxhlet extraction in a Soxtec ${ }^{T M} 1045$ apparatus (FOSS GmbH, Rellingen,

150 Germany) with boiling petroleum ether (Merck, Darmstadt, Germany). The defatted material

151 was transferred into steel cartridges, cooled down for 2-3 minutes with liquid nitrogen and

152 ground to yield a fine powder using a steel ball mill (TissueLyser Qiagen, Cat.No.85220,

153 Retsch $\mathrm{GmbH}$, Haan, Germany) for 3 min and $30 \mathrm{~Hz}$.

154 MBM, plant feed or bone powder was extracted by EDTA-extraction. All centrifugation steps

155 were performed at $15000 \mathrm{~g}, 10-20 \mathrm{~min}, 4^{\circ} \mathrm{C}$ in a Heraeus Multifuge $\AA 3 \mathrm{~S}+/ 3 \mathrm{SR}+($ Thermo

156 Scientific, Schwerte, Germany ). In brief, $2 \mathrm{~g}$ sample were extracted with $8 \mathrm{ml} 0.5 \mathrm{M}$

157 Ammonium EDTA ( $\mathrm{pH} 6.1$ ) by stirring at $4^{\circ} \mathrm{C}$ over night. The slurry was transferred into a

158 conical Falcon $^{\mathrm{TM}}$ tube and centrifuged. The supernatant was transferred into ultrafiltration

159 tubes with an exclusion size of $3000 \mathrm{Da}($ Amicon® Ultra Centrifugal Filters Ultracel-3K,

160 Millipore, Ireland) and the retained protein fraction was washed with $2 \mathrm{ml}$ phosphate buffered

161 saline (PBS, $10 \mathrm{mM} \mathrm{NaCl}, 10 \mathrm{mM} \mathrm{KCl}, 10 \mathrm{mM} \mathrm{Na}_{2} \mathrm{HPO}_{4},-\mathrm{NaH}_{2} \mathrm{PO}_{4}, \mathrm{pH}$ 7.4) to exchange the

162 buffer.

163 The protein concentration was measured for all extracts in triplicates using a Bicinchinonic

164 Acid Protein Assay Kit (Sigma-Aldrich, Saint Louis, Missouri, USA) according to the

165 manufacturer's instruction. All extracts (Table 1) were aliquoted and stored at $-80^{\circ} \mathrm{C}$ until

166 use. 
Antibodies

A commercial mouse monoclonal antibody binding to the epitope aa17 of bovine osteocalcin (OC4-30, Takara Bio Inc., Otsu/Shiga, Japan), specified to cross react with human, bovine, rabbit, sheep, dog, monkey and goat but not rat or mouse, was used as animal specific

172 capture antibody in a two-side sandwich ELISA. Polyclonal antibodies (PAB) were raised in

173 two rabbits against the synthetic and LPH- (Limulus polyphenus hemocyanin) coupled 174 osteocalcin amino acid sequence OC 1-9 (YLDHWLGAP) by a service laboratory (Biogenes, 175 Berlin). The best performing serum in a pre-test against BSA-coupled amino acid sequence 176 (PAB OC1-9) was purified by affinity chromatography on $\mathrm{CNBr}$-activated sepharose by the 177 service laboratory to isolate a monospecific lgG-fraction which was used in the sandwich 178 ELISA as secondary antibody. For this purpose PAB OC1-9 was conjugated with streptavidin 179 (PAB OC1-9-Strep) using a commercial kit according to the manufacturer's instruction 180 (Lightning-Link ${ }^{\mathrm{TM}}$ Streptavidin Conjugation Kit, Innova Biosciences, Cambridge, UK, 181 Technical Bulletin 1086, Release 02, June 2010).

182 183 Sandwich ELISA

184 Capture, secondary and detecting agent concentrations as well as the incubation time and 185 temperature were optimized in grid experiments. The final protocol was performed as follows.

186 Washing steps were repeated in general four times with $380 \mu \mathrm{l}$ PBS-Tween 20 (154 mM $187 \mathrm{NaCl}, 7.7 \mathrm{mM} \mathrm{Na}_{2} \mathrm{HPO}_{4}, 2 \mathrm{mM} \mathrm{NaH}_{2} \mathrm{PO}_{4}, 0.05 \%$ Tween 20, $\mathrm{pH}$ 7.4) using an automatic 188 ELISA Washer (Wellwash, Thermo Fisher Scientific). All incubation steps were carried out in 189 a volume of $100 \mu \mathrm{l} /$ well. $1 \mu \mathrm{g} / \mathrm{ml}$ of the capture antibody (OC4-30) was bound to a microtiter 190 plate (Maxisorp, Nunc ${ }^{\mathrm{TM}}$, Denmark) for $48 \mathrm{~h}$ at $4^{\circ} \mathrm{C}$. The plate was washed and then blocked 191 by adding $200 \mu \mathrm{l} /$ well Blocking Buffer made of $1.5 \%(\mathrm{w} / \mathrm{v})$ bovine albumine fraction $\mathrm{V}$ (BSA;

192 Merck, Darmstadt, Germany) in $10 \mathrm{mM}$ PBS, pH 7.4, overnight at $4{ }^{\circ} \mathrm{C}$. The plate was 193 washed and incubated with standard dilutions in PBS (1, 10, 100 and $1000 \mathrm{ng} / \mathrm{ml}$ 194 osteocalcin) or undiluted sample extract (Table 1) for $2 \mathrm{~h}$ at room temperature (RT). The 
195 plate was washed and incubated with detection antibody (PAB OC1-9-Strep; 1:500 in PBS)

196 for 2 h/RT, washed and incubated 1 h/RT with Biotinylated HRP (Invitrogen Corporation,

197 Camarillo, CA; 1:10.000 in PBS). The plate was washed and the assay developed with

198 chromogenic solution prepared as follows: $15 \mathrm{ml}$ of citrate buffer $(210 \mathrm{mM}$ citric acid

199 monohydrate, $300 \mathrm{mM} \mathrm{KOH}, \mathrm{pH} 3.95)$ and $13.6 \mathrm{mM}$ freshly added $\mathrm{H}_{2} \mathrm{O}_{2}$ were mixed 20:1

$200(\mathrm{v} / \mathrm{v})$ with $21.6 \mathrm{mM}$ TMB (3,3`,5,5`-Tetramethylbenzidine, BioChemica, AppliChem,

201 Darmstadt, Germany) diluted in $2.5 \mathrm{ml}$ acetone and $22.5 \mathrm{ml}$ methanol (p.A.). After incubation

202 for $20 \mathrm{~min} / \mathrm{RT}$ in the dark the reaction was stopped by adding $1 \mathrm{~N} \mathrm{H}_{2} \mathrm{SO}_{4}$ to each well. The

203 optical density was determined at $450 \mathrm{~nm}$ against air in a multimode plate reader (Mithras LB

204 940, Berthold Tech. GMBH \& Co. KG, Bad Wildbad, Germany). All samples and standards

205 were measured in triplicates, statistical relevance between two data sets was calculated by

206 two-side unpaired Student's t-test.

207

208 SDS-PAGE and Western blot

209 Discontinuous sodium dodecylsulfate polyacrylamide gel electrophoresis (SDS-PAGE) was

210 performed with Tris-Glycin buffer according to Laemmli (1970) using a Mini Protean® Tetra

211 System electrophoresis cell (Bio-Rad, Laboratories Inc., Germany). For the separation of low

212 molecular weight proteins the separating gel contained $16.5 \%$ and the stacking gel $7.5 \%$

213 acrylamide (Rotiphorese®Gel 30 [37.5:1]), Carl Roth GmbH \& Co KG, Karlsruhe, Germany).

214 Separated proteins in the gel were electro-transferred onto a nitrocellulose membrane

215 (Amersham ${ }^{\mathrm{TM}}$ Hybond $^{\mathrm{TM}}$-ECL, GE Healthcare) with a blotter unit (Bio-Rad, Laboratories Inc.)

216 at $4^{\circ} \mathrm{C}$ and $350 \mathrm{~mA} / 400 \mathrm{~V}$ for $1 \mathrm{~h}$ using transfer buffer as described by the blotter unit's

217 manual. The blot was blocked in PBS/3 \% BSA for 45 min at RT followed by an overnight

218 incubation at $4{ }^{\circ} \mathrm{C}$ with PAB OC1-9-Strep diluted $1: 500$ in PBS $/ 1.5 \%$ BSA. The membrane

219 was washed three times with TBST and PAB OC1-9-Strep binding onto the blot was

220 detected by biotinylated HRP (1:5.000 in PBS containing 1.5\% BSA) after $1 \mathrm{~h} / \mathrm{RT}$ incubation.

221 After washing the blot was developed by adding $750 \mu$ l of a ready-mixed developing solution

222 (Super Signal West Femto Maximum Sensitivity Substrate, Thermo Scientific) and chemo 
22

224

225

226

227

228

229

230

231

232

233

234

235

236

237

238

239

240

241

242

243

244

245

246

247

248

249

250

luminescence was measured with the Imaging System VersaDoc MP 4000 (Bio-Rad

Laboratories, Munich, Germany).

\section{Results}

In order to develop a sandwich ELISA for the detection of processed bovine osteocalcin $(\mathrm{OC})$, a rabbit polyclonal antibody was raised against the amino acid sequence 1-9 of pure bovine osteocalcin. The best performing pre-tested serum (PAB OC1-9) was monospecifically purified. To confirm the reactivity of the isolated mono-specific IgG fraction, an immunoblot was carried out with an EDTA protein extract produced from native bovine bone. Solely one major low-molecular weight protein band $(\sim 5.8 \mathrm{kDa})$ was detectable corresponding to the size of intact mature reference protein (Figure 2). No significant unspecific binding to other bone proteins occurred in bovine bone extract so that the antibody PAB OC1-9 could be used to establish a sandwich ELISA pair with a monoclonal mouse capture antibody (OC4-30).

The intra- and inter- assay variability and the sensitivity of the final ELISA set up was validated with standard dilutions of bovine osteocalcin in triplicates on three different days by the same operator (Figure 3). According to this validation experiment, the two-side assay is characterized by an average background signal ranging between $A_{450 \mathrm{~nm}} 0.170-0.260$ for the non template control (NTC; PBS instead of sample) and blank (PBS instead of capture MAB). A significant signal above NTC and blank was obtained - with a probability of $p<0.05$ in two-side Student's t-test - starting from an OC amount of $1 \mathrm{ng}$ per well. Above this value the standard deviation is rising along with increasing signal strength, but the calculated inter assay coefficient of variation $(2.8-23.3 \%)$ (Figure 3 ) was considered satisfactory for all concentration levels and the assay accepted for the scope of investigation.

EDTA extracts of native bone derived from most significant farmed animals as well as egg and milk protein and a compound plant feed used for BMBM spiking (Plant Feed-0 \% BMBM) 
251 were measured to evaluate the specificity of the test. All EDTA-extracts were applied

252 undiluted in ELISA, to ensure a maximum achievable response with highly processed

253 materials or matrices of low MBM content. Protein yields typically varied between $0.6-2.8$

$254 \mathrm{mg} / \mathrm{ml}$ for different bone and MBM extracts (Table 1). The EDTA extract with the highest

255 protein amount was gained from egg powder with approximately $4 \mathrm{mg} / \mathrm{ml}$.

256 The results of the specificity testing are summarized in Figure 4. The Limit of detection (LOD)

257 was calculated as the mean absorption $\mathrm{A}_{450}$ value plus 3-fold standard deviation of 13

258 different negative samples (measured in triplicate) which constitute typical feed compounds

259 (plant feed, whole milk powder, hen`s egg) or potential contamination with other species than

260 cattle (fish meal, poultry meal, sheep MBM, sheep bone, pork MBM, pork bone, chicken

261 bone, goat bone, rabbit bone) as well as the NTC. The horse sample has been excluded

262 from the calculation due to the $100 \%$ amino acid identity with bovine osteocalcin and could

263 therefore not been considered as a negative sample. In all following experiments the LOD

264 indicates the baseline to discriminate true positive from negative results. The strongest

265 ELISA signals $\left(\mathrm{A}_{450} \mathrm{~nm}>3\right)$ were detected for cattle and horse bone extracts. For these

266 samples absolute protein amounts of 55 to $75 \mu \mathrm{g} /$ reaction were sufficient to elicit a strong

267 ELISA response with signals rapidly out-of-range if using further increased input amounts.

268 Regarding bone extracts from other animals, a weaker but significant ELISA signal pointing

269 to an evident cross reaction was measured with $100 \%$ native pork bone extract. In a western

270 blot investigation with pure pig bone extract and PAB OC1-9 it was noticed, that a cross

271 reaction is directed against an unidentified protein of approximately $31 \mathrm{kDa}$ (data not shown).

272 In addition, a weak cross reaction was also monitored for $100 \%$ native sheep bone extract

273 (Figure 4). Bone extracts from chicken, goat or rabbit so as EDTA-extractable proteins from

274 hen's egg, whole milk powder or compound plant feed all yielded negative results below

275 LOD-Baseline. EDTA-extracts derived from goose- or salmon bone, feather meal, as well as

276 rye, maize and soybean were tested negative (data not shown).

277 
278 In the next step, the capacity of the immunoassay to detect $\mathrm{OC}$ in heat treated meat and

279 bone meal extracts was investigated, to test the applicability of the ELISA on real life 280 samples. Since no horse MBM was available, horse serum was used instead as an 281 exemplary matrix containing only trace amounts of osteocalcin. The total protein amount of 282 all employed undiluted MBM-extracts per ELISA well ranged in a comparable order of 283 magnitude between approx. 100 (poultry meal) $-280 \mu \mathrm{g}(\mathrm{BMBM})$. The results are depicted in 284 Figure 5. All BMBM samples showed a pronounced immunological response, even if the 285 material was heated up to $145^{\circ} \mathrm{C}$, whereas fish, poultry and sheep meal were tested 286 negative. Therefore the cross reaction with native sheep bone is judged negligible since it is 287 not interfering with the scope of the assay. A positive reaction was only detectable for undiluted horse serum and - in contrast to sheep meal - for pork MBM extract. Though the 289 immune response against porcine MBM was rather weak compared with BMBM (c.f. dog 290 feed), the obtained pork MBM signal exceeded the LOD-baseline (Figure 5).

291

292 The selectivity of the test was evaluated with extracts yielded from a standard plant feed 293 spiked with $0.1 \%(w / v)$ BMBM in comparison with the non-spiked matrix. In addition, since 294 no homogeneity approved material was available, dilutions of $0.1 \%$ BMBM (dog feed) in fish 295 meal extracts were measured (Figure 6). The test discriminated $0.1 \%(w / v ; v / v)$ BMBM296 spiked plant feed or fish meal, respectively, from the non-spiked matrix. The quantitative 297 content of osteocalcin in the plant feed spiked with $0.1 \%(\mathrm{w} / \mathrm{v})$ BMBM corresponds to $6.7 \mathrm{ng}$ 298 calculated in relation to the standard curve. Due to the observed cross reaction of the ELISA 299 with pig meal, a separate selectivity experiment was performed. $0.1 \%, 1 \%$ and $10 \%(\mathrm{v} / \mathrm{v})$ 300 BMBM (dog feed) extract in pig meal extract was measured on three days (Table 2). A 301 significant positive response was measurable for the $10 \%(\mathrm{v} / \mathrm{v})$ BMBM spiking level but not 302 for the $1 \%(\mathrm{v} / \mathrm{v})$ spiked sample. The absorption measured with $100 \%$ pork meal extract did 303 not exceed the values corresponding to $10 \mathrm{ng}$ bovine OC per well.

\section{Discussion}


306 A pre-requisite for the development of an immunological assay to detect fraudulent

307 application to or unintended traces of MBM in feed is the thorough choice of a protein which

308 exhibits exceptional resistance against mechanical forces, pressure and peak temperatures

309 up to $140-150^{\circ} \mathrm{C}$ evoked by the rendering process (Pérez-Calvo et al. 2010; Garcia et al.

310 2006). In this study the heat stable bone protein osteocalcin has proved to be a well suited

311 MBM marker since a strong immunological signal was still detectable in BMBM even if

312 processed at $145^{\circ} \mathrm{C}$. In addition, osteocalcin represents a genuine MBM- as well as animal

313 marker protein since it is exclusively expressed in bone tissue or dentin in all vertebrates

314 including bone fish (Hauschka et al. 1989).

315

316 Though fairly stable if bound to the hydroxyapatite skeleton, osteocalcin under natural

317 conditions undergoes rapid degradation in a turnover process in the blood plasma. Two

318 arginine-arginine cleavage sites are situated at the amino acid positions $19(\operatorname{Arg})-20(\operatorname{Arg})$ and

31943 (Arg)-44(Arg) (Figure 1) resulting in two to three fragments (aa1-19, aa20-43, aa44-49) on

320 tryptic hydrolysis. The cleavage site near the C-terminal sequence is quickly hydrolysed

321 cutting off the latter six amino acid residues whereas the resting aa1-43 fragment (N-MID

322 fragment) is far more stable (Lee et al. 2000). Respecting the binding sites of the antibodies

323 in our assay (aa1-9 and the epitope aa17) the results obtained with three different bovine

324 MBM samples underline that a significant portion of at least the N-MID (aa1-43) is still

325 immunologically accessible in MBM.

326

327 To restrict the assay specificity to cattle, the synthetic $\mathrm{N}$-terminal amino acid sequence aa1-9

328 of bovine osteocalcin was used for the immunization of rabbits to exclude other most relevant

329 farmed animals. The N-terminal sequences of osteocalcin in the genus Bos, Sus, Ovis and

330 Capra differ only in one to three amino acids whereas this sequence is completely identical

331 among Bos and Equus (Figure 1). The specificity testing confirmed that minor sequence

332 differences were sufficient to limit the major polyclonal antibody reactivity to Bos with the

333 predictable exception of Equus. However, an increasing tendency towards cross reaction is 
334 observed in accordance with the number of amino acid exchanges in relation to Bos OC aa13359 ranking from Capra (3 exchanges): no cross reaction - Ovies (2 exchanges): very weak 336 cross reaction - Sus (1 exchange): weak cross reaction - Equus (100\% sequence identity):

337 strong cross reaction. The observed binding of the polyclonal rabbit lgG fraction to a $31 \mathrm{kDa}-$

338 protein in western blot studies with PAB OC1-9 and porcine bone extract (data not shown) 339 points rather to an unspecific side reaction to another protein than osteocalcin. To unravel 340 the nature of this cross reaction a mass spectroscopic investigation would be required which 341 was not subject of this study. However, the exchange of the voluminous aromatic amino acid 342 tryptophan at position aa5 in bovine OC against glycine in Sus could be targeted by the 343 production of a high affinity monoclonal antibody.

In the case of horse and cattle a sequence difference between both is given only at position 346 aa19 where lysine in bovine osteocalcin is exchanged by arginine in the genus Equus

347 (Figure 1). Therefore elimination of cross reaction in theory could be possible by an 348 exchange of the capture antibody. However, an attempt to boost a polyclonal rabbit capture 349 antibody against the synthetic mid-fragment spanning aa16 - 22 of bovine osteocalcin was 350 not successful. This might be due to the lacking carboxylation of the glutamic acid residues 351 at position 17, 21 and 24 of the synthetic peptide used for immunization, preventing 352 appropriate molecule folding. In addition the hydrophobic core of the molecule (Dowd et al. 353 2003) most probably requires a conformational epitope rather than a sequence based 354 recognition site for antibody binding. The latter consideration is supported by a study using 355 monoclonal and polyclonal OC- directed antibodies which were tested with differently sized 356 fragments of the molecule. The authors demonstrated a generally poor affinity of antibodies 357 against OC fragments comprising solely of aa11-29 or aa21-43 (Gundberg et al. 1998). 358 Accordingly, the exclusion of horse- but also a reduction of pig cross reactivity could be 359 tackled by a compelling anti-protein production mode, e.g. as given by stringent phage 360 display or monoclonal selection against native bovine osteocalcin fragments aa1-43, aa1-19, 361 aa 4-19 or intact osteocalcin. The latter is planned for further investigations. 
363 Apart from osteocalcin, $\gamma$-carboxylated glutamic acids are occurring e.g. in proteins involved

364 in the blood coagulation cascade like prothrombin, but could not be detected so far in

365 hemolymph of annelids, crustaceous organisms, insects, soybean leafs, E. coli extract or

366 bovine milk (Zytkovicz and Nelsestuen 1976). Accordingly, the ELISA developed in this study

367 verified a remarkable selectivity for osteocalcin in plant background. A protein extract

368 prepared from a classical feed mix used for the preparation of $0.1 \%$ BMBM spiked feed

369 samples, yielded a background signal comparable with blank and NTC. Similar results were

370 obtained with $100 \%$ soybean-, wheat- or corn protein extracts and a further plant based milk

371 replacer containing $12 \%$ citrus and $5 \%$ cocoa shell (data not shown). The presence of beet

372 or citrus pulp obviously does not pose a problem in contrast to test interference observed for

373 these ingredients in a previous validation study on commercial test kits (Boix et al. 2004).

374 The selectivity of the assay was also excellent in fish meal background which is explainable

375 by the pronounced sequence differences between osteocalcin from bone fish compared with

376 terrestrial animals (Figure 1). In contrast, the observed weak but significant cross reactivity

377 with pure pig bone or pig meal decreased the selectivity of the assay. However, only one

378 sample of pure pork meal was available for testing so that further pork MBM materials as well

379 as defined mixtures have to be investigated to verify this result. Due to the nature of the

380 material a cross-contamination with bovine material could not be excluded. The identification

381 of MBM traces derived from other species - e.g. BMBM in pork or fish meal - seems to be a

382 most challenging issue associated with MBM targeted immunological methods which was

383 also observed for commercial cooked meat kits. In studies on the performance on two

384 broadly distributed dip stick tests increasingly false positive results were monitored in the

385 presence of $5 \%$ pork meal or animal fat or with fish meal at levels as low as $1.5 \%$ (Fumière

386 et al. 2009; Boix et al. 2004).

387

388 The percentage of bone fragments in two defined BMBM samples which we used in our

389 experiments was about 54 and $80 \%(w / w)$, which is the common range reported for 
390 materials from rendering plants (Liu et al. 2010). The good results yielded with EDTA as a 391 bone solvent is in line with recently published results on an improved extraction method for 392 the detection of ruminant material. Due to an EDTA-based extraction mode the performance 393 of a commercial dip stick test could be improved from $2 \%$ down to a detection level of $0.1 \%$ 394 BMBM in feed (Karanam 2011). In contrast to our approach the method includes a 395 concentration step of the bone fraction by sedimentation with $100 \mathrm{ml}$ tetra chloroethylene 396 (TCE) as used in sample preparation for microscopy (Regulation (EC) No 152/2009). An 397 additional density based concentration of bone fragments is not necessary for the ELISA 398 method described here avoiding an agent supposed to be carcinogenic (IPCS INCHEM; 399 http://www.inchem.org/). However, an over night bone digestion step which does not allow 400 rapid sample analysis within a few hours, was also applied in our study. To speed up the 401 extraction method used here the procedure could possibly be optimized by hot and/or acid 402 extraction or augmentation of the sample amount or further homogenization of coarse 403 fractions.

404

405 The bone content might play an essential role regarding the sensitivity of the method. The 406 question if an osteocalcin based method would also perform with samples containing $<54 \%$ $407(\mathrm{w} / \mathrm{w})$ bone or even with $100 \%$ muscle meal remains to be clarified with appropriate 408 materials which were not available in this study. With respect to the expectable great 409 variance of MBM from different rendering plants it would be anyhow advisable not only to rely 410 on one single target molecule but to apply a panel of well defined marker-proteins to capture 411 the great diversity of animal by-products produced by the rendering industry.

413 Although the sensitivity of our assay $1 \mathrm{ng}$ bovine $\mathrm{OC}$ is about one order of magnitude below 414 commercial osteocalcin ELISA validated for pharmaceutical applications, the sensitivity with 415 MBM looks encouraging compared with commercial ELISA test kits developed for the scope 416 of species detection in processed meat. For these, sensitivities of $0.1,0.5$ or $>=2 \% \mathrm{MBM}$ in 417 feed or even a complete failure to detect legally treated MBM have been reported from 


\begin{abstract}
418 diverse validation studies (Boix et al. 2004; Karanam 2011; Meyers et al. 2007; von Holst et 419 al. 2006; Rao and Hsieh 2007; Love and Carey-Smith 2004; Gizzi and von Holst 2004). The 420 sensitivity of the ELISA procedure used in our study primarily might have been decreased 421 during the mono-specific purification step retaining most potent binding IgG from the 422 polyclonal sera. The linkage to the voluminous streptavidine molecule had no negative 423 impact on the sensitivity compared with horseradish peroxidase labelling (data not shown) 424 but an enhancing effect due to multiple biotinylation sites.
\end{abstract}

425

\title{
426 Conclusions
}

427 In conclusion our results demonstrate that osteocalcin is a promising tissue specific target 428 protein for the sensitive immunological detection of meat and bone meal in compound feed 429 or fish meal with an excellent selectivity for BMBM in these matrices. Furthermore 430 environmental bone fragment contaminants in sugar beet epidermis, e.g. derived from rabbit, 431 rat or mouse can be easily discriminated because of marked sequence divergences to e.g. 432 bovine osteocalcin. The here described antibody-based osteocalcin approach might be the 433 basis for a validated detection tool for official law enforcement of the feed ban. Moreover the 434 general approach using epitop-specific antibodies is target-directed and might be an 435 improvement in terms of the acceptance as national or international standard in the future. 436 Moreover quantification is possible based on a standard curve established by commercially 437 available pure bovine osteocalcin.

438

\section{References}

440

441 Ansfield M. 1994. Production of a Sensitive Immunoassay for Detection of Ruminant Proteins

442 in Rendered Animal Material Heated to $>130{ }^{\circ} \mathrm{C}$. Food \& Agricultural Immunology. 6: 419$443 \quad 433$

444

445 Balizs G, Weise C, Rozycki C, Opialla T, Sawada S, Zagon J, Lampen A. 2011.

446 Determination of osteocalcin in meat and bone meal of bovine and procine origin using 
447 matrix-assisted laser desorption ionization/time-of-flight mass spectrometry and high-

448 resolution hybrid mass spectrometry. Analytica Chimica Acta. 693: 89-99

449

450

Boix A, Serano F, Bellorini S, von Holst C. 2004. RUGGEDNESS STUDY OF

451

IMMUNOASSAYS FOR PROCESSED ANIMAL PROTEINS DETECTION IN FEED: Neogen

452

453

454

455

456

Reveal for Ruminant Feed Test System. European Commission, DG JRC-IRMM, Geel,

Belgium. GE/R/FSQ/03/2006/09/04

457

Chen F-C, Hsieh Y-HP, Bridgman RC. 1998. Monoclonal Antibodies to Porcine Thermal-

Stable Muscle Protein for Detection of Pork in Raw and Cooked Meats. Journal of Food

458

459

Science. 63(2): 201-205

Chen F-C, Hsieh Y-HP, Bridgman RC. 2002. Monoclonal antibodies against troponin I for the 464 detection of rendered muscle tissues in animal feedstuffs. Meat Science. 62: 405-412

466 Communication from the Commission to the European Parliament and the Council

Collins MJ, Gernaey AM, Nielsen-Marsh CM, Vermeer C, Westbroek P. 2000. Slow rates of degradation of osteocalcin: Green light for fossil bone protein? Geology. 28(12): 1139-1142 on the TSE Roadmap 2. COM(2010)384. Brussels. SEC(2010) 899 final

Dowd TL, Rosen JF, Li L, Gundberg C M. 2003. The Three-Dimensional Structure of Bovine Calcium Ion-Bound Osteocalcin Using ${ }^{1} \mathrm{H}$ NMR Spectroscopy. Biochemistry. 42: 7769-7779 S, Gundberg C, Bradley A, Karsenty G. 1996. Increased bone formation in osteocalcindeficient mice. Nature. 382: 448-452

Fumière O, Veys P, Boix A, von Holst C, Baeten V, Berben G. 2009. Methods of detection, species identification and quantification of processed animal proteins in feedingstuffs.

Biotechnol. Agron. Soc. Environ.. 13(S): 59-70 
484 Gizzi G, von Holst C. 2004. Determination of Processed Animal Proteins, Including Meat and 485 Bone Meal, in Animal Feed. Journal of AOAC International. 87(6): 1334-1340 486

487 Gundberg CM, Nieman SD, Abrams S, Rosen H. 1998. Vitamin K Status and Bone Health: 488 An Analysis of Methods for Determination of Undercarboxylated Osteocalcin. Journal of 489 Clinical Endocrinology and Metabolism. 83(9): 3258-3266 490 491 Hauschka PV, Lian JB, Cole DEC, Gundberg CM. 1989. Osteocalcin and Matrix Gla Protein: 492 493

494 Karanam M. 2011. An improved protein extraction method for detecting ruminant material in 495 feed using lateral flow device dipsticks. Biotechnologie, Agronomie, Société et 496 Environnement. 15(S1): 25-29 497 498 Kim S-H, Huang T-S, Seymour TA, Wei C-I, Kempf SC, Bridgman CR, Clemens RA, An H. 499 2004. Production of Monoclonal Antibody for the Detection of Meat and Bone Meal in Animal 500 Feed. Journal of Agricultural and Food Chemistry. 52: 7580-7585

501

502 Kim S-H, Huang T-S, Seymour TA, Wei C-I, Kempf SC, Bridgman CR, Momcilovic D, 503 Clemens RA, An H. 2005. Development of Immunoassay for Detection of Meat and Bone 504 Meal in Animal Feed. Journal of Food Protection. 68(9): 1860-1865

505

506 Laemmli UK. 1970. Cleavage of Structural Proteins during the Assembly of the Head of 507 Bacteriophage T4. Nature. 227: 680-685

508

509 Laizé V, Martel P, Viegas CSB, Price PA, Cancela ML. 2005. Evolution of Matrix and Bone Y510 Carboxyglutamic Acid Proteins in Vertebrates. Journal of Biological Chemistry. 280(29):

$511 \quad 26659-26668$

512

513 Lee AJ, Hodges S, Eastell R. 2000. Measurement of osteocalcin. Ann Clin Biochem. 37: 432514446

515

516 Liu X, Han L, Veys P, Baeten V, Jiang X, Dardenne P. 2011. An Overview of the Legislation 517 and Light Microscopy for Detection of Processed Animal Proteins in Feeds. Microscopy

518 Research and Technique. 74(8):735-743

519 
520 Love JL, Carey-Smith GV. 2004. Immunoassay Kit Used to Detect the Presence of Bovine

521 Material in Processed Foods. Journal of AOAC International. 87(5): 1143-1147

522

523 Meyers MJ, Yancy HF, Farrell DE, Washington JD, Deaver CM, Frobish RA. 2007.

524 Assessment of Two Enzyme-Linked Immunosorbent Assay Tests Marketed for Detection of

525 Ruminant Proteins in Finished Feed. Journal of Food Protection. 70(3): 692-699

526

527 Muldoon MT, Onisk DV, Brown MC, Stave JW. 2004. Targets and methods for the detection

528 of processed animal proteins in animal feedstuffs. International Journal of Food Science and

529 Technology. 39: 851-861

530

531 Muyzer G, Sandberg P, Knapen MHJ, Vermeer C, Collins M, Westbroek P. 1992.

532 Preservation of the bone protein osteocalcin in dinosaurs. Geology. 20(10): 871-874

533

534 Nielsen-Marsh CM, Richards MP, Hauschka PV, Thomas-Oates JE, Trinkaus E, Pettitt PB,

535 Karavanic I, Poinar H, Collins MJ. 2005. Osteocalcin protein sequences of Neanderthals and

536 modern primates. PNAS. 102(12): 4409-4413

537

538 Nishimoto SK, Waite JH, Nishimoto M, Kriwacki RW. 2003. Structure, Activity, and

539 Distribution of Fish Osteocalcin. Journal of Biological Chemistry. 278(14): 11843-11848

540

541 Pérez-Calvo E, Castrillo C, Baucells MD, Guada JA. 2010. Effect of rendering on protein and

542 fat quality of animal by-products. Journal of Animal Physiology and Animal Nutrition. 94(5):

543 e154-e163

544

545 Rao Q, Hsieh Y-HP. 2007. Evaluation of a commercial lateral flow feed test for rapid

546 detection of beef and sheep content in raw and cooked meats. Meat Science. 76: 489-494

547

548 Regulation (EC) No 999/2001 OF THE EUROPEAN PARLIAMENT AND OF THE COUNCIL

549 of 22 May 2001 laying down rules for the prevention, control and eradication of certain

550 transmissible spongiform encephalopathies. Official Journal of the European Communities.

551 2001R0999- EN-20.04.2009 - 033.001- 5.

552

553 Regulation (EC) No 1069/2009 OF THE EUROPEAN PARLIAMENT AND OF THE

554 COUNCIL of 21 October 2009 laying down health rules as regards animal by-products and

555 derived products not intended for human consumption and repealing Regulation (EC) No 
556 1774/2002 (Animal by-products Regulation). Official Journal of the European Union. L 300:

$557 \quad 1-33$

558

559 Regulation (EC) No 152/2009 of 27 January 2009 laying down the methods of sampling and

560 analysis for the official control of feed. Official Journal of the European Union. L 54: 1-130

561

562 Ulrich MMW, Perizonius WRK, Spoor CF, Sandberg P, Vermeer C. 1987. Extraction Of

563 Osteocalcin From Fossil Bones And Teeth. Biochemical and Biophysical Research

564 Communications. 149(2): 712-719

565

566 Vermeer C, Soute BAM, Hendrix H, de Boer-van den Berg MAG. 1984. Decarboxylated bone

567 Gla-protein as a substrate for hepatic vitamin K-dependent carboxylase. Federation of

568 European Biochemical Societies. 165(1): 16-20

569

570 von Holst C, Boix A, Baeten V, Vancutsem J, Berben G. 2006. Determination of processed

571 animal proteins in feed: The performance characteristics of classical microscopy and

572 immunoassay methods. Food Additives and Contaminants. 23(3): 252-264

573

574 Zytkovicz TH, Nelsestuen GL. 1976. y-Carboxyglutamic Acid Distribution. Biochimica et 575 Biophysica Acta. 444: 344-348 
Figure 1. Comparison of osteocalcin sequences published for farmed animals, pets, rodents, amphibian and bone fish species. Conserved carboxylated glutamic acid residues at position 17,21 and 24 are asterisked. Black arrows point to tryptic cleavage sites. Amino acid exchanges between Bos and other farmed animals are highlighted in bold types. The position of the sequence targeted by the detection antibody PAB OC1-9 and the N-MIDfragment (1-43) are marked by black lines. The capture antibody OC4-30 (Takara) used in the sandwich assay in this study binds to the epitope around position 17.

Figure 2. Specificity of PAB OC1-9 (polyclonal anti-osteocalcin IgG-fraction) towards native bovine bone protein in western blot analysis. M, Lane 2: Low-Range Molecular Weight Marker (3.5-40 kDa), Amersham, GE Healthcare; Lane 1: NTC (water instead protein); Lane 3: OC=Positive Control (bovine osteocalcin, $1.3 \mu \mathrm{g} / \mathrm{slot}$ ); Lane 4: BB=bovine bone EDTA extract $(7.2 \mu \mathrm{g} / \mathrm{slot})$

Figure 3. Osteocalcin specific sandwich ELISA with MAB OC4-30 (Takara) as capture and PAB OC1-9 as detection antibody. Sensitivity with purified bovine osteocalcin. Error bars indicate a one-fold standard deviation. Measurements were done in three replicates on three different days. Blank=PBS instead of capture; NTC= PBS instead of sample; *significant difference $(p<0.05)$ against NTC and Blank.

Figure 4. Osteocalcin specific sandwich ELISA with MAB OC4-30 (Takara) as capture and PAB OC1-9 as detection antibody. Specificity with EDTA-extracts from native bone and feed components. Error bars indicate a one-fold standard deviation. Undiluted EDTA extracts were measured in triplicate. Horizontal line $=$ LOD $=$ Mean $+3 x$ SD from 13 negative samples as indicated in the results section.

Figure 5. Osteocalcin specific sandwich ELISA with MAB OC4-30 (Takara) as capture and PAB OC1-9 as detection antibody. Method performance with meat and bone meal extracts. Error bars indicate a one-fold standard deviation. Undiluted EDTA extracts were measured in triplicate. Horizontal line $=\mathrm{LOD}=$ Mean $+3 \times$ SD from 13 negative samples as indicated in the results section.

Figure 6. Osteocalcin specific sandwich ELISA with MAB OC4-30 (Takara) as capture and PAB OC1-9 as detection antibody. Selectivity in mixtures containing $0.1 \%$ bovine MBM. Error bars indicate a one-fold standard deviation. Undiluted EDTA extracts were measured in triplicate. Horizontal line $=\mathrm{LOD}=$ Mean $+3 x$ SD from 13 negative samples as indicated in the results section. 
Comparison of osteocalcin sequences published for farmed animals, pets, rodents, amphibian and bone fish species. Conserved carboxylated glutamic acid residues at position 17, 21 and 24 are asterisked. Black arrows point to tryptic cleavage sites. Amino acid exchanges between Bos and other farmed animals are highlighted in bold types. The position of the sequence targeted by the detection antibody PAB OC1-9 and the N-MID-fragment (1-43) are marked by black lines. The capture antibody OC4-30 (Takara) used in the sandwich assay in this study binds to the epitope around position 17. $248 \times 164 \mathrm{~mm}(150 \times 150 \mathrm{DPI})$ 
Specificity of PAB OC1-9 (polyclonal anti-osteocalcin IgG-fraction) towards native bovine bone protein in western blot analysis. M, Lane 2: Low-Range Molecular Weight Marker (3.5-40 kDa), Amersham, GE Healthcare; Lane 1: NTC (water instead protein); Lane 3: OC=Positive Control (bovine osteocalcin, 1.3 $\mu \mathrm{g} / \mathrm{slot})$; Lane 4: BB=bovine bone EDTA extract $(7.2 \mu \mathrm{g} / \mathrm{slot})$ $100 \times 106 \mathrm{~mm}(150 \times 150 \mathrm{DPI})$ 
Osteocalcin specific sandwich ELISA with MAB OC4-30 (Takara) as capture and PAB OC1-9 as detection antibody. Sensitivity with purified bovine osteocalcin. Error bars indicate a one-fold standard deviation. Measurements were done in three replicates on three different days. Blank=PBS instead of capture; NTC= PBS instead of sample; *significant difference $(p<0.05)$ against NTC and Blank. $210 \times 143 \mathrm{~mm}(150 \times 150 \mathrm{DPI})$ 
Osteocalcin specific sandwich ELISA with MAB OC4-30 (Takara) as capture and PAB OC1-9 as detection antibody. Specificity with EDTA-extracts from native bone and feed components. Error bars indicate a onefold standard deviation. Undiluted EDTA extracts were measured in triplicate. Horizontal line $=$ LOD $=$ Mean $+3 x$ SD from 13 negative samples as indicated in the results section. $165 \times 92 \mathrm{~mm}(150 \times 150 \mathrm{DPI})$ 
Osteocalcin specific sandwich ELISA with MAB OC4-30 (Takara) as capture and PAB OC1-9 as detection antibody. Method performance with meat and bone meal extracts. Error bars indicate a one-fold standard deviation. Undiluted EDTA extracts were measured in triplicate. Horizontal line $=$ LOD $=$ Mean $+3 x$ SD from 13 negative samples as indicated in the results section. $166 \times 90 \mathrm{~mm}(150 \times 150 \mathrm{DPI})$ 
Osteocalcin specific sandwich ELISA with MAB OC4-30 (Takara) as capture and PAB OC1-9 as detection antibody. Selectivity in mixtures containing $0.1 \%$ bovine MBM. Error bars indicate a one-fold standard deviation. Undiluted EDTA extracts were measured in triplicate. Horizontal line $=$ LOD $=$ Mean $+3 x$ SD from 13 negative samples as indicated in the results section. $166 \times 90 \mathrm{~mm}(150 \times 150 \mathrm{DPI})$ 
Table 1. Protein concentration of EDTA extracts used in ELISA

\begin{tabular}{ll}
\hline & $\begin{array}{l}\text { Protein } \\
\text { concentration } \\
\text { of the } \\
\text { undiluted } \\
\text { extract used } \\
\text { per well }[\mathrm{mg}]\end{array}$ \\
\hline BMBM. $145^{\circ} \mathrm{C}$ & 0.278 \\
BMBM. $133^{\circ} \mathrm{C}$ & 0.283 \\
BMBM dog feed & 0.124 \\
Plant Feed $0.1 \%(\mathrm{w} / \mathrm{w}) \mathrm{BMBM}$ & 0.094 \\
Plant Feed $0 \% \mathrm{BMBM}$ & 0.068 \\
fish meal & 0.193 \\
pork MBM & 0.124 \\
sheep MBM & 0.182 \\
poultry meal & 0.098 \\
bovine bone & 0.055 \\
sheep bone & 0.163 \\
goat bone & 0.267 \\
pork bone & 0.242 \\
chicken bone & 0.182 \\
rabbit bone & 0.117 \\
horse bone & 0.075 \\
horse serum & 0.878 \\
hen`s egg & 0.406 \\
whole milk powder & 0.231 \\
\end{tabular}


Table 2. Selectivity in osteocalcin specific sandwich ELISA. using MAB OC4-30 (Takara) as capture and PAB OC1-9 as detection antibody. for hidden BMBM in pork meal in three independent measurements

\begin{tabular}{llllll}
\hline Extract & Day 1 & Day 2 & Day 3 & Mean & SD \\
\hline BMBM dog feed & 3.469 & 3.352 & 3.501 & 3.441 & 0.078 \\
Pork MBM & 0.677 & 0.753 & 0.586 & 0.672 & 0.084 \\
$10 \%$ BMBM in pork MBM & 0.887 & 1.116 & 1.232 & 1.078 & 0.176 \\
$1 \%$ BMBM in pork MBM & 0.525 & 0.561 & 0.595 & 0.560 & 0.035 \\
$0.1 \%$ BMBM in pork MBM & 0.476 & 0.524 & 0.514 & 0.505 & 0.025
\end{tabular}

